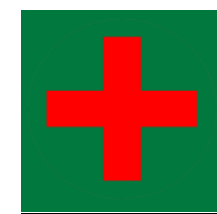

\title{
Implementasi Masase Neuroperfusi dan Alih Baring Terhadap Risiko Dekubitus Pasien Post Stroke
}

\author{
Erika Martining Wardani ${ }^{1}$, Riezky Faisal Nugroho ${ }^{2}$ \\ ${ }^{1}$ Fakultas Keperawatan dan Kebidanan, Universitas Nahdlatul Ulama Surabaya, \\ Surabaya, Indonesia \\ ${ }^{2}$ Jurusan Gizi, Poltekkes Kemenkes Surabaya, Surabaya, Indonesia \\ Email: 1erika@unusa.ac.id, ${ }^{2}$ riifan7@gmail.com
}

\begin{abstract}
Decubitus is a problem in post-stroke patients that has yet to be resolved. The risk of pressure sores can be overcome with neuroperfusion massage therapy and bed rest. The purpose of this study was to determine the implementation of neuroperfusion massage and bed transfer on the risk of pressure sores in post-stroke patients. The design of this research is Quasy-Experiment with pre post test control group design. The population of all post-stroke patients treated at the Arosbaya Health Center in the Bangkalan Madura area was 30 people. A sample of 28 stroke patients was taken using a simple random sampling technique. The independent variable is neuroperfusion massage and bed transfer, the dependent variable is the risk of pressure sores. Data were analyzed using the Wilcoxon Signed Rank Test. The results showed that after the intervention of neuroperfusion massage ( $p$ value 0.000) and bed transfer (0.000) there was a reduction in the risk of pressure sores in post-stroke patients. Neuroperfusion massage and bed transfer are effective in preventing the risk of pressure ulcers in post-stroke patients. It is hoped that health workers can apply bed transfer therapy with neuroperfusion massage so that pressure sores can be handled optimally.
\end{abstract}

Keywords: Neuroperfusion Massage, Bed Transfer, Decubitus, Post Stroke.

\begin{abstract}
Abstrak
Dekubitus menjadi masalah pada pasien post stroke yang sampai saat ini belum bisa teratasi. Risiko dekubitus dapat diatasi dengan terapi masase neuroperfusi dan alih baring. Tujuan penelitian ini adalah untuk mengetahui implementasi masase neuroperfusi dan alih baring terhadap risiko dekubitus pasien post stroke. Desain penelitian ini Quasy-Experiment dengan pre post test control group design. Populasi semua pasien post stroke yang dirawat di wilayah Puskesmas Arosbaya Bangkalan Madura sebanyak 30 orang. Sampel sebagai penderita stroke sebanyak 28 orang diambil dengan tehnik simple random sampling. Variabel independen dengan masase neuroperfusi dan alih baring, variabel dependen risiko dekubitus. Data dianalisis menggunakan Uji Wilcoxon Signed Rank Test. Hasil menunjukkan sesudah intervensi massase neuroperfusi ( $\mathrm{p}$ value 0,000$)$ dan alih baring $(0,001)$ terhadap penurunan risiko dekubitus pasien post stroke. Masase neuroperfusi dan alih baring efektif dilakukan untuk mencegah terjadinya risiko dekubitus pada penderita post stroke. Diharapkan tenaga kesehatan dapat dengan menerapkan terapi alih baring dengan masase neuroperfusi sehingga kejadian decubitus dapat tertangani dengan optimal.
\end{abstract}


Kata Kunci: Neuroperfusion Massage, Bed Transfer, Decubitus, Post Stroke.

\section{PENDAHULUAN}

Dekubitus menjadi masalah yang sampai saat ini belum bisa teratasi dan masih menjadi sebuah ancaman dalam pelayanan kesehatan karena insidennya semakin hari semakin meningkat. Dekubitus ini banyak terjadi pada pasien yang mengalami gangguan mobilitas seperti pasien post stroke dan fraktur tulang belakang. Banyak penderita yang tidak mengetahui perawatan bedrest sehingga jika tidak mendapatkan perawatan yang baik menimbulkan resiko dekubitus. Saat ini masih banyak terdapat pasien stroke yang mengalami dekubitus tersebut lebih banyak terjadi pada bagian tulang belakang atau punggung (Sari, 2018).

Prevalensi dekubitus di study International seluruh dunia mencapai 63.6\%, di Indonesia mencapai 33,3\% terbilang masih tinggi dibandingkan di ASEAN (Eropa, Amerika, Inggris dan Singapura). Angka kejadian dekubitus menurut data Riskesdes (2018) di Jawa Timur mencapai 55,3\%, di Madura mencapai 50.3\%, di Kabupaten Bangkalan mencapai 43,4\%. Berdasarkan sensus kependudukan dan demografi Indonesia (SKDI) tahun 2016 sebanyak 1 juta setiap tahun dengan prevalensi 6,1 per 1000 penduduk. Hasil terjadinya dekubitus secara umum dilaporkan bahwa 5-11\% terjadi pada perawatan acut care, $15-25 \%$ diperawatan jangka panjang dan $7-12 \%$ ditatanan perawatan homecare. Kerusakan integritas kulit pada pasien yang terkena ulkus dekubitus mengakibatkan terjadinya infeksi. Berdasarkan studi pendahuluan yang diperoleh peneliti ditemukan data awal di Puskesmas Arosbaya pada pasien stroke berisiko mengalami ulkus dekubitus di dapatkan hasil 36 pasien dalam tiga bulan terakhir tahun 2020.

Penderita stroke yang mengalami tirah baring lama dapat menyebabkan luka dekubitus. Luka dekubitus disebabkan oleh beberapa faktor yaitu imobilisasi, gaya gesek, kelembaban kulit, penurunan fungsi sensorik dari gerak tubuh dalam jangka waktu yang lama. Imobilisasi dan gaya gesek mengakibatkan tekanan terutama pada area penonjolan tulang. Tekanan menyebabkan iskemia dan hipoksemia pada jaringan yang terkena, mengingat aliran darah ke tempat tersebut berkurang. Sedangkan kelembaban meningkatkan maserasi kulit (pelunakan akibat basah) dan menyebabkan epidermis lebih mudah terkikis dan menghambat aliran darah. Terhambatnya aliran darah akan menghalangi oksigenisasi dan nutrisi ke jaringan yang mengkontribusi untuk terjadi nekrosis pada jaringan kulit. Nekrosis pada jaringan kulit yang tidak segera ditangani akan berkembang secara bertahap hingga ke jaringan otot dan tulang. Apabila sudah terjadi nekrosis pada otot dan tulang dapat pula bertahap pada bagian tendon dan sendi. (Kozier, 2012).

Upaya untuk mengatasi masalah tersebut adalah ultrasound diatermi, stimulasi listrik, laser, posisi alih baring, masase punggung, masase olive oil, masase dengan virgin coconut oil dan masase neuroperfusi. Hal ini sesuai dengan penelitian Luwih dan Akhyar (2017) salah satu upaya pencegahan terjadinya risiko dekubitus yaitu dilakukan masase neuroperfusi untuk penanganan nyeri dan gangguan fungsi. Posisi alih baring ini adalah pengaturan posisi yang diberikan untuk mengurangi tekanan dan gaya gesek pada kulit, menjaga bagian kepala tetap tidur dan menurunkan peluang terjadi dekubitus 
akibat gaya gesek. Alih baring yang dilakukan oleh perawat dengan rentang waktu kurang lebih 2 jam (Sari, 2018). Masase neuroperfusi yang dapat melancarkan sirkulasi, metabolism, melepaskan pelekatan dan melancarkan peredaran darah. Masase neuroperfusi ini dilakukan selama 15 menit yang dapat memberikan efek relaksasi dan mengurangi tekanan pada tubuh (Luwih dan Akhyar, 2017). Berdasarkan latar belakang tersebut peneliti tertarik melakukan penelitian dengan judul "Implementasi masase neuroperfusi dan alih baring terhadap risiko dekubitus pada post stroke".

\section{METODE}

Penelitian ini menggunakan penelitian Quasy-Experiment dengan pendekatan pre post test control groub design. Populasi dalam penelitian ini adalah semua pasien dengan penyakit stroke yang mengalami tirah baring di Wilayah Kinerja Puskesmas Arosbaya Bangkalan sebanyak 30 responden. Sampel yang digunakan adalah 28 pasien yang dibagi menjadi 2 kelompok yaitu 14 pasien kolompok kontrol dan 14 pasien kelompok intervensi. Sampel dipilih dengan teknik simple random sampling. Penelitian dilakukan selama 1 bulan dr bulan April-Mei 2021.

Dalam penelitian ini, instrument penelitian yang akan digunakan untuk pelaksanaan masase neuroperfusi dan alih baring menggunakan SOP yang telah disusun oleh peneliti. Instrumen untuk menilai risiko dekubitus menggunakan lembar observasi dengan skor Norton untuk mengetahui ada atau tidaknya risiko dekubitus pada penderita post stroke.

Hasil data yang sudah terkumpul di lakukan coding atau dikoreksi melalui lembar observasi, kemudian dianalisis risiko dekubitus sebelum (pre) dan sesudah (post) dilakukan masase neuroperfusi dan alih baring pada kelompok intervensi dan kelompok kontrol dengan menggunakan uji statistic Wilcoxon Signed Rank Test dengan tingkat kemaknaan $\alpha=0.05$.

\section{HASIL}

\section{1) Karakteristik responden}

Tabel 1. Karakteristik responden

\begin{tabular}{|lccc|}
\hline No & Variabel & $\begin{array}{c}\text { Jumlah } \\
(\mathbf{n = 2 8})\end{array}$ & $\begin{array}{c}\text { Prosentase } \\
(\mathbf{\%})\end{array}$ \\
\hline 1. & Usia (tahun) & 5 & \\
$\leq 45$ & 14 & 17,9 \\
& $45-60$ & 9 & 50 \\
& $\geq 60$ & & 32,1 \\
& Jenis kelamin & 12 & 42,9 \\
& Laki-laki & 16 & 57,1 \\
& Perempuan & 16 & \\
\hline
\end{tabular}


3. Lama menderita stroke

$$
\begin{array}{lcc}
\leq 1-3 \text { bulan } & 14 & 50 \\
\geq 1-3 \text { bulan } & 14 & 50
\end{array}
$$

Berdasarkan tabel 1 diperoleh hasil bahwa responden setengahnya berusia 45-60 tahun $(50 \%)$, berjenis kelamin mayoritas perempuan $(57,1 \%)$, dengan lama menderita post stroke rata-rata 1-3 bulan.

\section{2) Implementasi masase neuroperfusi terhadap risiko dekubitus pada post stroke}

Tabel 2. Implementasi masase neuroperfusi terhadap risiko dekubitus pada post

\begin{tabular}{|c|c|c|c|c|c|c|c|}
\hline \multirow[t]{2}{*}{ Kelompok } & \multirow[t]{2}{*}{ n } & \multicolumn{2}{|c|}{$\begin{array}{c}\text { Sebelum masase } \\
\text { neuroperfusi }\end{array}$} & \multirow[t]{2}{*}{$p$ value } & \multicolumn{2}{|c|}{$\begin{array}{c}\text { Setelah masase } \\
\text { neuroperfusi }\end{array}$} & \multirow[t]{2}{*}{$p$ value } \\
\hline & & Mean & SD & & Mean & SD & \\
\hline Intervensi & 14 & 2,26 & 0,621 & 0,105 & 4,00 & 0,000 & 0,001 \\
\hline Kontrol & 14 & 2,67 & 0,436 & & 2,37 & 0,428 & \\
\hline
\end{tabular}
stroke

Berdasarkan tabel diatas menunjukkan bahwa terdapat pengaruh masase neuroperfusi. Hasil uji Wilcoxon didapatkan $p$ value $0,001 \quad(\mathrm{p}<0,05)$ maka dapat disimpulkan bahwa Ha diterima, artinya ada pengaruh yang bermakna risiko decubitus pada penderita post stroke sebelum dan setelah diberikan masase neuroperfusi.

\section{3) Implementasi alih baring terhadap risiko dekubitus pada post stroke}

Tabel 3. Impelemntasi alih baring terhadap risiko dekubitus pada post stroke

\begin{tabular}{cccccccc}
\hline Kelompok & $\mathbf{n}$ & \multicolumn{2}{c}{ Sebelum VCT } & $\boldsymbol{p}$ value & \multicolumn{2}{c}{ Setelah VCT } & $\boldsymbol{p}$ value \\
\cline { 3 - 4 } \cline { 3 - 4 } & & Mean & SD & & Mean & SD & \\
\hline Intervensi & 14 & 2,50 & 0,532 & 2,76 & 2,81 & 0,482 & 0,000 \\
Kontrol & 14 & 2,55 & 0,631 & & 2,83 & 0,467 & \\
\hline
\end{tabular}

Tabel 3 menunjukkan bahwa terdapat alih baring dengan hasil uji Wilcoxon didapatkan $p$ value $0,000(\mathrm{p}<0,05)$ maka dapat disimpulkan bahwa Ha diterima, artinya ada pengaruh alih baring sebelum dan setelah diberikan pada penderita post stroke.

\section{PEMBAHASAN}

1) Implementasi masase neuroperfusi terhadap risiko dekubitus pada post stroke

Hasil penelitian yang dilakukan oleh peneliti menunjukkan hasil bahwa ada pengaruh implementasi masase neuroperfusi terhadap risiko dekubitus pada post stroke.

Hal ini sejalan dengan penelitian Setyawati (2012) bahwa teknik masase punggung sekali atau dua kali sehari lebih efektif daripada mobilisasi setiap 2-3 jam 
dalam mencegah perkembangan luka tekan. Masase punggung mencegah terjadinya infeksi melalui pengaktifan sistem kekebalan pada tekanan, seperti yang diamati pada pasien tirah baring di tempat tidur.

Penelitian yang dilakukan oleh Wardani (2019), dengan masase yang dilakukan menyebabkan sirkulasi darah menjadi lancar dengan efek yang langsung dirasakan ke saraf-saraf sehingga dalam darah tidak terjadi endapan gula dan darah yang membawa oksigen dan nutrisi yang akan disampaikan keseluruh bagian dapat mengalir sehingga dengan sirkulasi baik menyebabkan seseorang bisa merasa lebih rileks.

Alih baring adalah tindakan yang dilakukan untuk mengubah posisi pasien yang mengalami tirah baring total untuk mencegah kejadian luka tekan pada kulit pasien. Pada dasarnya alih baring dilakukan sebagai bagian dari prosedur baku dalam intervensi keperawatan untuk mengurangi resiko dekubitus pada pasien dengan imobilisasi. Posisi alih baring dilakukan dengan cara memiringkan pasien dari terlentang ke miring maupun sebaliknya bisanya posisi alih baring harus diberikan kepada penderita hemiplegia dan koma dengan kurun waktu setiap 2 jam ke arah kanan dan 2 jam ke arah kiri (Potter \& Perry, 2012). Alih baring dengan masase neuroperfusi adalah tehnik baru masase untuk memperlancar oksigen pada aliran darah/limfe dari jantung ke organ perifer dan sebaliknya dengan tujuan mengembalikan fungsi sensorik dan motorik. Tehnik masase ini harus dikerjakan secara lembut dan mantap. Prosedur massage diawali pada daerah utama/pusat (thorax dan lumbal), diikuti daerah perifer (cervical, brachial, femoral, pedis dll) tergantung pada keluhan pasien. Sebagai tanda lancarnya oksigen dan relaksasi otot, semakin lama prosedur massage akan semakin nyaman dan hilang rasa sakit/ pain free. Biasanya pada awal prosedur masase, pasien akan merasakan kesakitan. Setelah $8-10$ kali masase, rasa sakit akan berangsurangsur hilang. Hal ini diduga karena asam laktat yang mulai mencair dan tidak menumpuk lagi (Luwih dan Akhyar, 2017).

Pasien stroke yang mengalami imobilisasi tidak bisa melakukan gerakan secara mandiri harus dibantu oleh orang lain dan pasien yang mengalami kelumpuhan atau koma karena salah satu sistem dalam anggota tubuhnya mengalami gangguan, bila pasien hanya posisi terlentang dalam waktu yang cukup lama bisa mengalami dekubitus, maka harus dilakukan posisi alih baring untuk mencegah terjadinya bedrest dengan alih baring menggunakan massage neuroperfusi.

\section{2) Implementasi alih baring terhadap risiko dekubitus pada post stroke}

Hasil penelitian yang dilakukan oleh peneliti menunjukkan hasil bahwa ada pengaruh implementasi alih baring terhadap risiko dekubitus pada post stroke.

Stroke adalah gangguan fungsi saraf yang disebabkan gangguan aliran darah dalam otak yang dapat timbul secara mendadak dalam beberapa detik atau secara cepat dalam beberapa jam (Amin, 2015). Pada pasien stroke biasanya mengalami imobilisasi atau tirah baring dikarenakan penekanan mempengaruhi metabolisme seluler dengan menurunkan atau menghambat sirkulasi jaringan, yang akhirnya akan menimbulkan iskemik jaringan dan nekrosis. Iskemik jaringan adalah tidak terdapatnya darah atau penurunan sebagian besar aliran darah yang terlokalisir akibat dari sumbatan. Ketika pasien dalam posisi berbaring atau duduk, berat badan tubuh tertumpu pada tonjolantonjolan tulang. Semakin lama penekanan terjadi, maka semakin besar pula 
resiko kulit untuk mengalami kerusakan. Pada saat tertekan tersebut dijauhkan, terjadi periode dari reaktif hiperemia atau peningkatan darah yang tiba-tiba ke area tersebut, ini disebut sebagai respon atau kompensasi dan ini hanya akan berguna apabila tekanan pada kulit di jauhkan sebelum terjadi nekrosis (Crisp \& Taylor, 2014).

Pasien post stroke dengan masalah gangguan mobilisasi yang mengalami alih baring di tempat tidur dalam waktu yang cukup lama tanpa mampu untuk merubah posisi akan berisiko tinggi terjadinya dekubitus. Pengaturan posisi alih baring masih belum konsisten pada setiap pasien dan masih belum dipandang serius, terlihat pada saat penelitian masih banyak pasien post stroke tidak dalam posisi yang benar. Decubitus menimbulkan sebuah ancaman dalam pelayanan kesehatan karena insidennya semakin hari semakin meningkat sehingga mengakibatkan penderita akan mengalami infeksi pada punggung sehingga jika tidak dilakukan alih baring setiap 2 jam maka decubitus akan semakin parah.

\section{KESIMPULAN DAN SARAN}

Ada pengaruh implementasi masase neuroperfusi dan alih baring terhadap risiko dekubitus pasien post stroke.

Pentingnya pemberian implementasi terutama masase neuroperfusi dan alih baring oleh perawat sebagai salah satu tindakan nonfarmakologi bisa diberikan kepada pasien dengan masalah gangguan mobilisasi dan tirah baring yang lama sehingga dapat mengurangi resiko kejadian kekubitus pada penderita terutama post stroke.

\section{DAFTAR PUSTAKA}

Amin, N dan Hardhi Kusuma. (2015). Nanda Nic-Noc Jilid 3. Yogyakarta : Mediaction.

Crisp \& Taylor, Black, M. J. (2014). Keperawatan Medikal Bedah: Manajemen Klinis Untuk Hasil Yang Diharapkan. Edisi 8. Buku 3. Singapore: Elsiever.

Kozier. Barbara. (2012). Buku Ajar Fundamental Keperawatan: Konsep, Proses dan Praktik, Penerjemah Widiarti. Jakarta: EGC.

Luwih Bisono \& Akhyar, H.N (2017), Prosedur Masase Neuroperfusi Untuk Penanganan Nyeri dan Gangguan Fungsi : Inovasi dan Modalitas Baru dalam Terapi Nyeri. Jurnal Anastesiologi Indonesia, 9(1), 1-9 https://doi.org/10.14710/jai.v9i1.19818

Potter, P.A \& Perry,Va.G. (2012). Buku Ajar Fundamental Keperawatan: Konsep, Proses dan Praktik. Edisi 7. Jakarta: EGC.

Riset Kesehatan Dasar (Riskesdas) (2018). Badan Penelitian dan Pengembangan Kesehatan Kementerian RI tahun 2018. Jakarta : Kemenkes.

Sari, E.D. (2018), Pengaruh Pemberian Virgin Coconut Oil (Vco) Pada Area Tertekan Untuk Mencegah Luka Tekan Pada Pasien Tirah Baring". Jurnal Proners, 3(1) http://dx.doi.org/10.26418/jpn.v3i1.27108

Setyawati. (2012). Pengaruh mobilisasi dan penggunaan VCO (Virgin Coconut Oil) terhadap ulkus dekubitus pada gangguan motorik pasca stroke di RS Islam Sultan Agung Semarang 
Wardani, dkk. (2019). Pengaruh Spa Kaki Diabetik Terhadap Kualitas Tidur Dan Sensitivitas Kaki Penderita Diabetes Mellitus Tipe 2, 7(2), 130-141. http://journal.wima.ac.id/index.php/NERS/issue/view/281. 